\title{
TRAS LAS PISTAS DEL ENSAYO
}

* Todo hombre dethe ensayar, pensundo a solas. hablando con su projimo, escribiendo y quira pablicando, mientras hable, escribe o publique de cuctiones yie fo caestionin:

León Sigifredo Ciro $R$.

Profesor Universidad Autónoma de Manizales

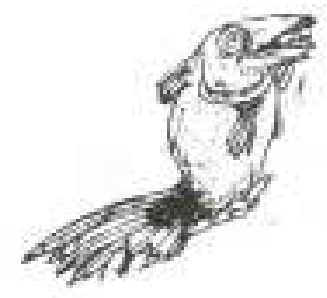

ara el ejercicio de escribir este Ensayo sobre el Ensayo, tengo al menos dos posibilidades de partida: La primera está referida a un propósito práctico: intentar un ejemplo acerca de lo que es un Ensayo a través de un escrito tipo Ensayo. La segunda posibilidad de partida está dada en los textos de Gabriel Zaid ( Negándose a recitar\%, en: Poesiaen la pràctica, Fondo de Cultura Económica, México 1985) y de Maria Femanda Palacios ( $\alpha$ Miserias y fulgores del Ensayo en la Venezuela de hoy», en; Saber y sabor de la Lengua, Monte A vila, Caracas 1987). textos ambos en que los autores referidos «Ensayan * sobre el Ensayo.

Y si hablo de dos posibles puntos de partida para escribir este Ensayo, es para significar que el géne- 
ro ensayistico asume los puntos de partida como multiples y variables, pero que desconoce los puntos de llegada, en virtud de lo que señala Maria Fernanda Palacios cuando dice que el Ensayo sno afirma ni responde, sino que incita a interrogars ( $\mathrm{Pag}$. 111).

Busco en consecuencia, con lo anterior, otro punto de partida y se me antoja bucear en el sentido oculto del titulo de este trabajo $\alpha$ Tras las pistas del Ensayon. El sustantivo "pistasn se me revela provocador , pistasm lo asocio con claves, tambien con caminos y avenidas, rutas de transito, de recepcion o de partida. Y si Ensayar, en este sentido, constituye un ejercicio del pensamiento, metaforicamente podria plantearse la existencia de pistas o caminos o avenidas por las que transitan las ideas y los conceptos ya no sólo para Ensayar. sino también para encontrar o asignar significado al mundo.

En este sentido. propongo a continuacion algunos caminos de trảnsito para las ideas en relación con el Ensayo:

\section{LA PARADOJA DE LA SERPIENTE}

Literalmente, una serpiente al cazar se traga entera a su victima. Pero a veces, cuando se enrosca. por una extraña equivocación, confunde su cola con una victima y empieza a devorarse a si misma, a tragarse entera asi misma.

Da gusto pensar que por acto propio la culebra opera la magia de su desaparición, aunque en la realidad ese fenómeno no pucde ocurrir. debido a que la longitud de la culebra se conserva como una sumatoria de la parte de si misma que puede tragarse. y de la que no puede tragarse.

De la misma manera, al escribirse un Ensayo con tema EI Ensayom, puede operarse la paradoja de la serpiente: que termine negándose $o$ afirmándose como Ensayo. Es decir. debe hablar del Ensayo de manera Ensayistica o postuiar lo que en si mismo no puede ejemplificar.

En otras dimensiones ocurre lo mismo. Juan $\mathrm{Pa}$ blo Castel. por ejemplo, refiere la anécdota del Poeta Lartigue que escribió un libro sobre la vanidad de los seres humanos, pero que se quejaba por no haber recibido el Premio Nacional de Poesia. O el caso de muchos politicos que se declaran de izquierda pero que viven una cotidianidad al extremo conservadora, $O$ el de muchos maestros que proclaman la creatividad como la panacea de la educacion, pero que no pueden urabajar sinel manual bajo el brazo. O el caso de las feministas que viven su vida como una caricatura del machismo más obsoleto. $O$ el del filosofo que maneja al dedillo la estetica escrita en los libros de Kant, pero que sólo ve carne en los cuerpos femeninos que no caminan sino que danzan en los pasillos de la Universidad, etc. etc

De las expresiones del pensamiento tal vezel Ensayo es la que mejor encarna la paradoja de la serpiente. Lo que postula se vuelve sobre si mismo para negarlo o para afirmarlo. Es, dicho de otra manera. un cjercicio del pensamiento dirigido hacia un objeto. pero que vuelve sobre el pensamiento a modo de interrogación. También constituye el mejor ejemplo del deber ser de la condición humana: actuar reflexionando la actuacion. Es llevar al limite lo que escribio Fernando Gonzalez: wadie puede transmitir la belleza que no poseen.

\section{LOS PUNTOS DE REFERENCIA}

Dice Maria Fernanda Palacios que uEl Ensayo es (...) hijo o hermano del diálogon. (Pag. 111). Tambien afirma que «El Ensayo. antes de ocuparse de las ideas de otro. de las teorias de otro, es un trabajo de reflexion, un trabajo re-llexivo, donde el sujeto que escribe se convierte en el asunto mismo de la indagacións. (Pag. 110). Pues bien, creo que el diálogo del pensamiento de un individuo que ensaya puede darse en la disertación consigo mismo, o en el diálogo-debate-interrogación con ideas o concep-

\section{Universidad Autónoma de Manizales}


tos que sirven como punto de referencia.

Mi reflexión, mi pensamiento en este caso, asume como avenida los puntos de referencia de Zaid y Palacios, que concuerdan en una cosa: el caracter interrogativo del Ensayo, el diálogo consigo mismo y con otros, la flexibilidad, la ausencia de verdades absolutas.

Deduzco de lo anterior, un componente que me parece definitivo del Ensayo: su apertura al fuego y a la aventura que no puede interpretarse como irresponsabilidad. En un mundo tan reglado, tan normatizado como el que vivimos, los espiritus aventureros no dejan de parecerme una promesa. Frente al orden impuesto, los aventureros se ven como contestatarios y rebeldes. Yo sólo los veo como los buscadores de otras posibilidades que la norma prohibe.

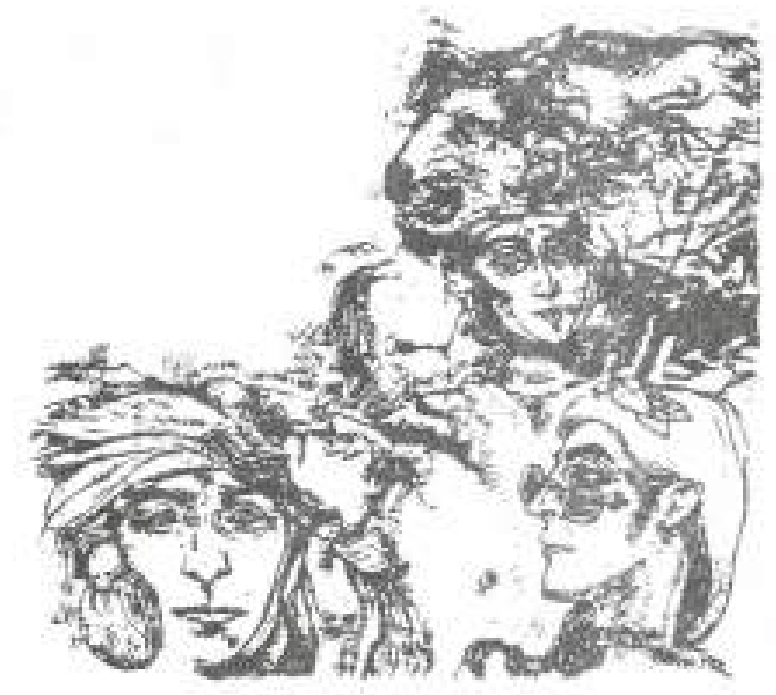
guerra. hacer negocios, para inventar máquinas e incluso para acceder a las mieles del amor, del poder o de la

\section{L.A PISTA PARA EL JUEGO}

Anies mencioné que el juego es otro componente del Ensayo. Ahora se me ocurre que no es propiamente un wcomponente" sino su manera de ser. Ensayar es un ejercicio preparatorio, una prueba. no una demostración. Ensayar a exponer, a interrogar, a encontrarse. Por eso dice Maria Fernanda Palacios que el Ensayo se origina en la kdebilidads y en la "modestian, y nunca en la certidumbre ni la ostentación. El Ensayo no es demostrativo sino inquisitivo. por lo tanto lúdico. El juego de buscar, Cucli - Cucli (o escondidijo) me parece un simil interesante a propósito de lo que propongo sobre el Ensayo. El encanto del juego, su magia, radica en la búsqueda, en el escondite. en no dejarse encontrar. El

Por su parte, la aventura es pariente del juego y del riesgo. Tal vez el arte $y$ la ciencia nacen en el resgo, en la superación del limite, en la exploración de lo no imaginado, en el enfrentamiento a lo desconocido. En este sentido, el Ensayo puede partir de lo conocido y de lo imaginado, pero no se repite. explora más allá de lo imaginado. Ensayar, pues, es una manera de asumir la herencia de la cultura humana. Porque, sobre qué, sino sobre la capacidad de búsqueda y de aventura, se ha estructurado la culturahumana?

Quede claro, sin embargo, que la busqueda, la interrogación y la aventura son condiciones del Ensayista, pero no exclusivamente del Ensayista. Muchos seres humanos urilizan esas caracteristicas para
Ensayista huce lo mismo; explora caminos, examina indicios, interroga, se contradice, vuelve sobre si mismo para rearsudar o para diseñar atajos. Yo pienso que en los origenes de la ciencia, del arte y de la cultura está el juego. El homo ludens es anterior al homo sapiens, y esa puede ser una vía para la erradicación del utilitarismo y del pragmatismo que catacterizan a nuestra época.

Por eso, hacer Ensayo, escribir Ensayo, en este tiempo de las certezas, de la productividad y del rendimiento económico, constituye un magnifico ejemplo de romanticismo o de utopia: aportarle al sueño de ver la vida más cercana al disfrute y más lejara de la productividad como modelo humano, a toda costa. 